九州大学学術情報リポジトリ

Kyushu University Institutional Repository

\title{
Assessment of Screw Types for the Development of Continuous Combined Grater-Presser Machine for Cassava Grates Processing
}

Jack 0. Bertulfo

Department of Agricultural and Biosystems Engineering, College of Engineering and Geosciences, Caraga State University

https://doi.org/10.5109/4738579

出版情報: Proceedings of International Exchange and Innovation Conference on Engineering \& Sciences (IEICES). 7, pp. 136-142, 2021-10-21. 九州大学大学院総合理工学府 バージョン:

権利関係: 


\title{
Assessment of Screw Types for the Development of Continuous Combined Grater- Presser Machine for Cassava Grates Processing
}

\author{
Jack O. Bertulfo $1,2^{*}$ \\ ${ }^{1}$ Department of Agricultural and Biosystems Engineering, College of Engineering and Geosciences, Caraga State \\ University, Butuan City, 8600, Philippines \\ ${ }^{2}$ Center for Resource Assessment, Analytics and Emerging Technologies (CReATe), Caraga State University, Butuan \\ City, 8600, Philippines \\ "Corresponding author email: jobertulfo@ carsu.edu.ph
}

\begin{abstract}
This study was conducted to develop a machine that continuously operates two processing operations (grating and pressing) for cassava grates production. Due to a lack of concrete literature for the type of screws to be used for the continuous dewatering operation for cassava, three types of screws were evaluated to identify which is the most suitable screw to be used. The screws were tested using five (5) $\mathrm{kg}$ cassava tubers as input materials and the capacity and rate of moisture removal were measured as a response. The variable pitch screw failed to show its performance due to the failure occurs during evaluation. A t-test analysis was used to analyze the significant difference between the remaining two screws. The analysis shows that the tapered screw shaft shows the most promising results having an average output capacity of $5.35 \mathrm{~kg} / \mathrm{hr}$ and rate of moisture removal of $4.69 \mathrm{~kg} / \mathrm{hr}$.
\end{abstract}

Keywords: Cassava Grates, Dewatering, Screw

\section{INTRODUCTION}

Mechanization of agricultural processing operations to increase the efficiency and capacity of every process has been the focus of the interest of engineers, innovators, and scientists throughout the years. However, it is complicated because most agricultural products are nonhomogeneous, making it difficult to understand. Hence, understanding the critical stage/component of every operation including the properties of the material is needed to have a better design.

On the other hand, cassava (Manihot esculenta Crantz), which originated from Brazil and Paraguay, is one of the major sources of dietary energy of billions of people around the world. Cassava is being processed to convert its highly perishable roots into more stable products, eventually increasing its economic value. Furthermore, the processing of cassava had yielded products that are easily available and affordable demand of starch-based diet other than an animal-based meal. According to Kadurumba et al. [1], even though cassava indisputably remains a significant food or cash crop of the tropical world, the mechanization of its field of operation remains meager and relatively insignificant due to lack of concrete achievement or actual machines on the global market. Among all researches and innovations on improving the cassava processing operations, the grating operation is considered as the most successful in terms of mechanization while peeling remains to have insignificant results.

In the Philippines, cassava is also regarded as one of the most important crops which can be used as food, ingredient for feeds, and source for numerous products including starch, flour, and bioethanol. Moreover, at least 218,000 farmers are partially/fully dependent on cassava production and about 15 million Filipinos are consuming cassava as a staple and supplemental to rice. In 2017, about 234,500 hectares of land is being cultivated producing 2.8 million metric tons of cassava [4]. With these productions, about 2.3 million metric tons of cassava is being used for processing.

Cassava is commonly processed into a different form of value-added products such as flour and dried grates which can be processed into other products. Such food products are normally used to produce baked products and other value-added products. Processing of cassava into dried cassava grates was focused on this study.

The processing of dried cassava grates involves several processes such as peeling, grating, pressing/dewatering, pulverizing, and drying. Among all those operations, pressing/dewatering is second to peeling as the most laborious operation in the processing of dried cassava grates. This operation is also considered as a pre-drying stage that will eventually help in reducing energy consumption during the drying operation. Equipment such as hydraulic press, power screw press, and a spinner are the most common equipment used to dewater freshly grated cassava. All of these machines are operated in batch mode which makes it laborious and time-consuming. Moreover, excessive contact with cassava in the skin of the operator was found to be hazardous as reported by Kolawole, et al. [2] which makes a batch type dewatering machine disadvantageous. A continuous dewatering machine for cassava mash is also available as designed by Kolawole et al. [2] and Kadurumba et al. [1] specific for cassava flour production. Such machine was not reported yet as being used for dewatering freshly grated cassava. There was also an attempt of developing combined grater and presser as reported by Kolawole et al. [3] but failed to publish a concrete result showing the success of the machine. Hence, the development of continuous combined grater-presser machine specific for the production of grates is highly needed but the problem of which screw type to use arise. Hence, the objective of the study is to conduct a comparative evaluation of different screw types for combined grater-presser machine.

\section{MATERIALS AND METHODS}

Grating then dewatering is a series of operation in the processing of cassava grates. Currently, both operations utilized a separate machine for each process. Cassava grater is one of the most successful machines in the processing of cassava. On the other hand, dewatering operations utilized a spinner machine which is laborious due to its mode of operations (batch type). Since the said 
operations are a series of operations, designing a single machine that will operate both operations is more advantageous compared to the existing machines in terms of its ease of operation. However, since the current mode of operation of the spinner is in batch mode, the concept of utilizing similar operation principle seems impossible. Hence, this study aimed to design a continuous mode of dewatering for cassava grates and will be connected to the grater to form a single machine that will operate two operations (grating and dewatering). The mechanism in oil expeller was adopted in the designed dewatering system.

\subsection{Combined Grater-Presser Machine}

The working design of the combined grater-presser machine is shown in Figure 1. The machine is composed of three main parts, the grater, screw conveyor, and the dewatering screw. The evaluation focused on the dewatering screw or the pressing section of the machine.

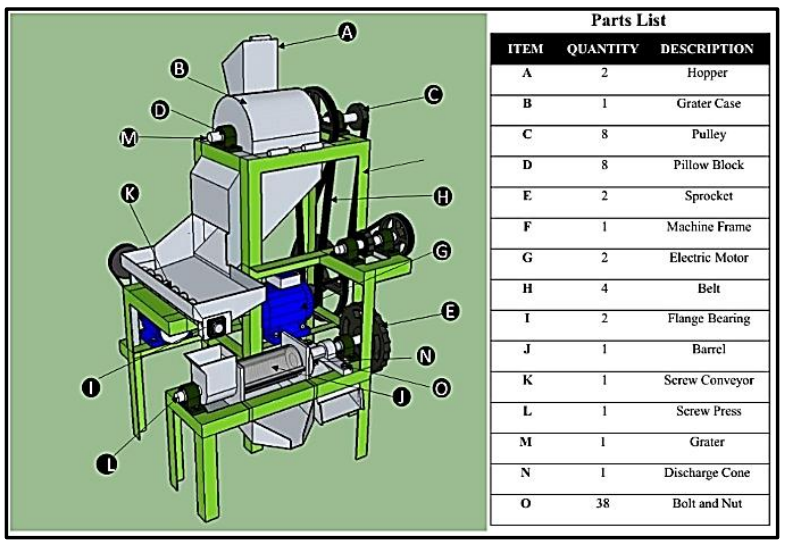

Fig 1. Working Design of the Machine.

\subsection{Presser Design}

The configuration of one of the pressers was adopted from the design of an oil-palm expeller machine which utilized a tapered screw configuration. A modification was conducted in terms of its pitch distance and compression ratio. The compression ratio is much lower compared to the reference design because of the property of the material to be processed. The barrel was an adopted design from the existing dewatering machine for sludge but a modification was employed in the hole diameter of the barrel.

The presser was made up of two main components, the screw, and the barrel. Three types of the screw were developed in this research, namely, straight screw, variable pitch screw, and tapered shaft screw.

\subsubsection{Shaft and Thread}

The shaft was the main component of the presser and the force that acted upon it was the weight of the grated cassava, screw thread, and pulleys. The same thing for the shaft in the grater, the shaft was designed in such a way that it is safe from bending and torsional stresses. Hence, the diameter of the press shaft was calculated using Equation 1. For tapered screw which utilized a special form of the shaft, the dimension was obtained using Equation 2.

$r=\frac{\tau L}{\emptyset G}$
$U_{n}=a+(n-1) d$

Each screw had varied designs according to their compression ratio. The compression ratio for straight, variable pitch and tapered screws are 1, 1.5, and 3, respectively. It was obtained using Equation 3.

$C R=\frac{h_{f}}{h_{m}}=\frac{V_{f}}{V_{d}}$

The configuration of the three screws were presented in the following Figure 2, 3 and 4.

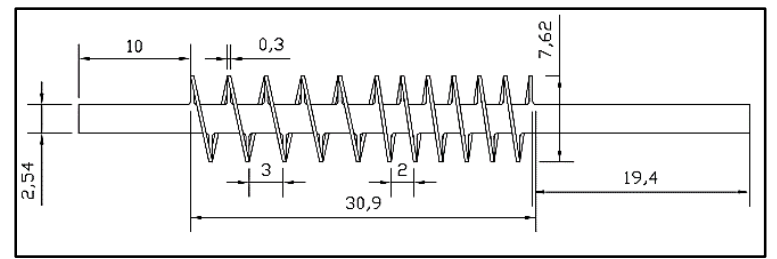

Fig 2. Variable Pitch Screw.

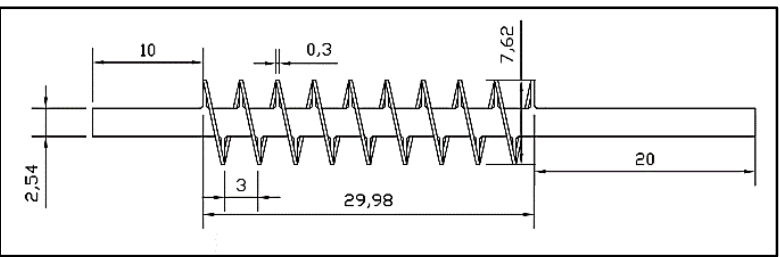

Fig 3. Straight Screw.

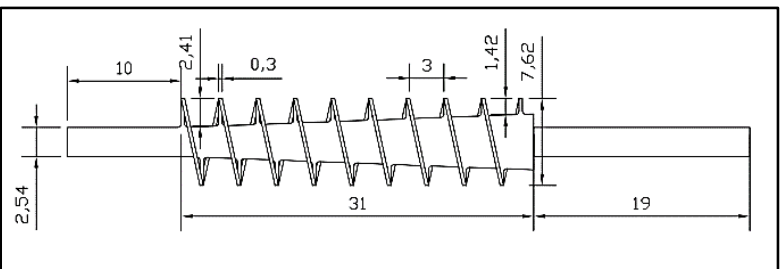

Fig 4. Tapered Screw.

\subsubsection{Barrel}

The barrel acted like a cylindrical vessel. The barrel was designed to withstand the pressure developed by the screw press. Having an inside diameter of $80 \mathrm{~mm}$ and a thickness of $5 \mathrm{~mm}$, the designed barrel can withstand a pressure of about $17.04 \mathrm{MPa}$. It was obtained using Equation 4.

$P_{b}=\frac{2 t \delta_{a}}{D_{i}}$

\subsection{Material Selection and Fabrication}

A one-inch diameter stainless rod was used for straight and variable pitch screw. The same thing was done in the fabrication of screw conveyor, each tread of the three screws was made using a metal plate. For tapered screw, the shaft was fabricated from a 2-in. diameter and $60-\mathrm{cm}$ long stainless rod which was machined on the lathe forming a $2.54-\mathrm{cm}$ shaft base 
diameter. Thereafter, the effective length was machined again to form a tapered shaft with a taper angle of $3.12^{0}$. After the fabrication of the shaft, the cut screw blade was fabricated in the main shaft of every screw.

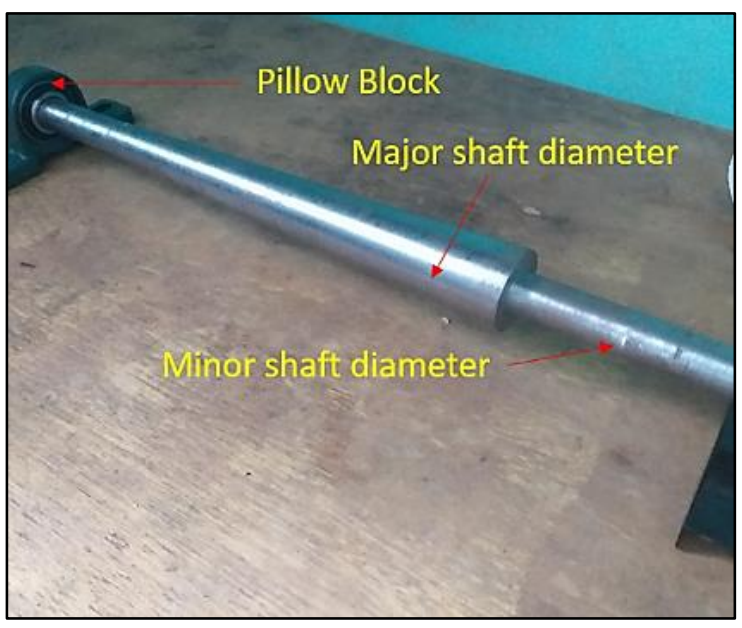

Fig 5. Machined Tapered Shaft.

\subsection{Experimental Setup and Performance Evaluation}

A series of two experiments were conducted in this study. First was the evaluation of the three types of screw. Second was the evaluation of the machine using the suitable screw with another set of factors. Five (5) $\mathrm{kg}$ of peeled cassava tubers were used as an input material to test the performance of the screw. Three (3) runs per screw for a total of nine (9) runs for the whole experiment. During the first evaluation, other factors were held constant like the speed of presser and discharge clearance of the presser. Following the first experiment, the combined grater-presser machine was tested using the suitable screw and subjected to five (5) levels of angular speed $(10,13,20,27$ and $30 \mathrm{rpm})$ and presser discharge clearance $(2,3,5,7$ and $8 \mathrm{~mm})$. A suitable Central Composite Design (CCD) for estimating the response surface with 11 treatments ( 8 non-center points and 3 center points) was used in the second experiment.

\subsection{Data Gathered}

The following data were gathered in this experiment:

1. The moisture content of the grated cassava and pressed cassava grates

2. Weight of the moisture removed and pressed cassava grates

3. Total operating time in each run

The following variables/parameters were determined:

1. Rate of moisture removal, $\mathrm{kg} / \mathrm{h}$

2. Machine input capacity, $\mathrm{kg} / \mathrm{h}$

3. Machine output capacity, $\mathrm{kg} / \mathrm{h}$

\subsubsection{Determination of Moisture Content $\left(\mathrm{MC}_{\mathrm{wb}}\right)$ of Grates}

A sample of freshly grated cassava was taken to determine its initial moisture and another sample was taken after pressing to determine its final moisture content. The moisture content of the samples was determined using the oven-dry method. The sample was placed in the oven for overnight to attain its bone-dry weight. The moisture content wet basis was calculated using Equation 5 below. Using the initial and final moisture content of the grates, the moisture difference was calculated using Equation 6 below. The extracted moisture was collected using a basin and then weighed. The rate of moisture removal can be determined using the weight of the moisture extracted and total operating time. The rate of moisture removal was calculated using Equation 7.

$$
\mathrm{MC}_{\mathrm{wb}}=\frac{\mathrm{w}_{\mathrm{i}}-\mathrm{w}_{\mathrm{f}}}{\mathrm{w}_{\mathrm{i}}} \times 100
$$

Where:

$\mathrm{MC}_{\mathrm{wb}}=$ moisture content wet basis, \%

$\mathrm{W}_{\mathrm{i}}=$ initial weight of the sample, $\mathrm{g}$

$\mathrm{W}_{\mathrm{f}}=$ final weight of the sample, $\mathrm{g}$

$$
\mathrm{MD}=M C_{i}-M C_{f}
$$

Where:

$\mathrm{MD}=$ moisture difference, $\%$

$\mathrm{MC}_{\mathrm{i}}=$ initial moisture content, $\%$

$\mathrm{MC}_{\mathrm{f}}=$ final moisture content, $\%$

$\mathrm{R}_{\mathrm{MR}}=\frac{\mathrm{WMR}-\mathrm{SCR}}{\mathrm{T}}$

Where:

$\mathrm{R}_{\mathrm{MR}}=$ rate of moisture removal, $\mathrm{kg} / \mathrm{h}$ WMR = weight of moisture removed, $\mathrm{kg}$ $\mathrm{SCR}=$ starch content recovered, $\%$ $\mathrm{T}=$ operating time, $\mathrm{hr}$

\subsection{Statistical Analysis}

A t-test analysis was conducted to analyze the data gathered during the first experiment using SPSS software. This analysis was used to determine the significant difference between screws. The data gathered in the second experiment was analyzed statistically following the Response Surface Methodology (RSM) method. The software used in the analysis was Design Expert v.10.

\section{RESULTS AND DISCUSSION}

\subsection{Machine Description and Working Principle}

The combined grater-presser machine consisted of three main components: grater, feeding auger, and screw press. Each of those components had its subcomponents which were important for the whole machine system. Figure 6 below shows the actual prototype of the fabricated combined grater-presser machine. In operation, the freshly peeled cassava tubers were introduced at the grater hopper while the grating drum was responsible for converting peeled cassava tubers into grated cassava. The grated cassava slowly moved through the screw conveyor which was responsible for conveying grated cassava into the screw press. The screw press conveyed and pressed the grated cassava inside the perforated cylindrical barrel. The extracted moisture was drained out through the perforated part of the barrel. The pressed grates were discharged at the grates outlet and were collected. The discharge outlet was designed in such a way that it helped further pressing of cassava grates as it went to the outlet. 


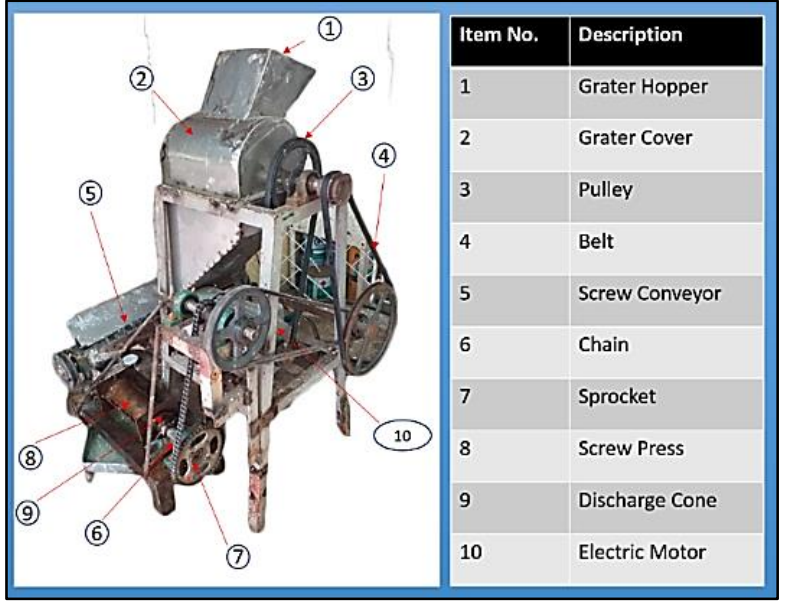

Fig 6. Combined Grater-Presser Machine.

\subsection{Performance of Different Screw Type}

After the fabrication of the combined grater-presser machine. The evaluation for the comparative evaluation between screw types follows. Three (3) types of screws were evaluated based on its capacity (input and output) and its ability in removing excess moisture before drying. Each screw was tested on three (3) runs with $5 \mathrm{~kg}$ of peeled cassava of each run. The fabricated screw is presented in Figure 7.

During the pre-evaluation, all screws performed well except for the variable pitch screw. The pressure exerted by the variable pitch screw was too much that it caused a serious failure in the machine. The pillow block holding the screw was not able to stand the pressure exerted by the screw which resulted to its breakage (Fig. 8). It can be concluded that among all other screws, the variable pitch screw exerted too much pressure.

It can be supported by the statement of Sari [5] that the pressure exerted by the variable pitch screw was higher compared to tapered and straight screw. With the failure of gathering data in its capacity and ability to remove moisture, the variable pitch screw was rejected for further evaluation.

The evaluation continued focusing on the comparative evaluation between the tapered screw and the straight screw. The results in the evaluation of two screw types with constant presser angular speed and discharge clearance (16 rpm and $3 \mathrm{~mm}$, respectively) is presented in Table 3. It is shown in the table that in terms of its ability in removing excess moisture, the tapered screw was more capable with an average of moisture removal of $14.78 \%$ and an average pressed grates moisture content of $47.59 \%$ wet basis. In terms of its input and output capacity, the tapered screw was also more promising than the straight screw with an average input capacity of $18.02 \mathrm{~kg} / \mathrm{h}$ and output capacity of 5.35 $\mathrm{kg} / \mathrm{h}$. An independent sample t-test was conducted to determine if all measured parameters were statistically different from each other. The result shows sufficient evidence that all measured parameters between tapered and straight screw were statistically different from each other with $99 \%$ level of confidence. It can be concluded that tapered screw was the best type of screw to be used and will undergo further evaluation of the combined grater-presser machine.

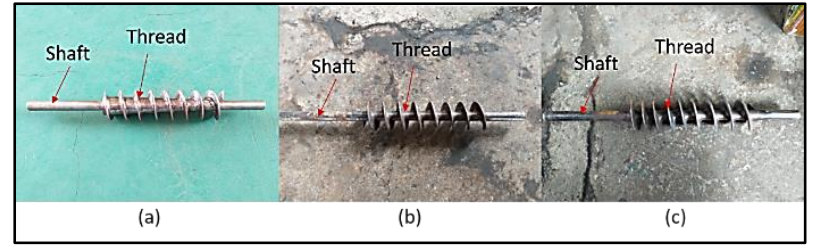

Fig 7. The different types of screws evaluated: (a) tapered screw, (b) variable pitch screw, and (c) straight screw.

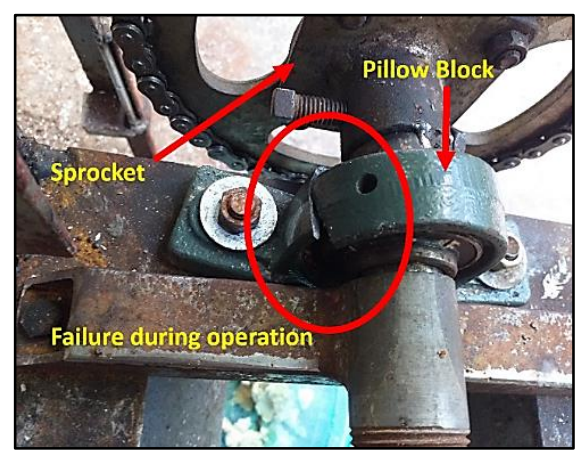

Fig 8. Failure of pillow block caused much pressure exerted by variable pitch screw.

Table 1. Summary of the results in the evaluation of different screw types.

\begin{tabular}{ccccc}
\hline $\begin{array}{c}\text { Screw } \\
\text { Type }\end{array}$ & $\begin{array}{c}\text { Pressed } \\
\text { grates } \\
\text { moisture } \\
\text { content } \\
(\%)\end{array}$ & $\begin{array}{c}\text { Moisture } \\
\text { removal } \\
(\%)\end{array}$ & $\begin{array}{c}\text { Rate of } \\
\text { moistur } \\
\text { e } \\
\text { remova } \\
1(\mathrm{~kg} / \mathrm{h})\end{array}$ & $\begin{array}{c}\text { Output } \\
\text { capacit } \\
(\mathrm{kg} / \mathrm{h})\end{array}$ \\
\hline $\begin{array}{c}\text { Tapered } \\
\text { screw }\end{array}$ & $47.59^{\mathrm{a}}$ & $14.78^{\mathrm{a}}$ & $4.69^{\mathrm{a}}$ & $5.35^{\mathrm{a}}$ \\
$\begin{array}{c}\text { Straight } \\
\text { screw }\end{array}$ & $52.54^{\mathrm{b}}$ & $10.04^{\mathrm{b}}$ & $1.96^{\mathrm{b}}$ & $1.95^{\mathrm{b}}$ \\
\hline
\end{tabular}

- Numbers with different letters are significantly different at $1 \%$ level of significance

\subsection{Machine Moisture Removal Performance}

The performance of the machine was evaluated using another set of parameters: the presser angular speed and the discharge clearance. The moisture content of the freshly grated and pressed cassava grates was determined in relation to the different treatment combinations. Three (3) subsamples were taken each run and were placed in the oven for 24 hours to reach its bone dry weight. Figure 9 shows the subsamples being placed in the oven for moisture determination. The objective was to determine the effect of the independent variables in the moisture content of the pressed cassava grates. Its effect on the rate of moisture removal, moisture difference, and weight of the moisture removed were also determined. The summary of the results is presented in Table 2 . 


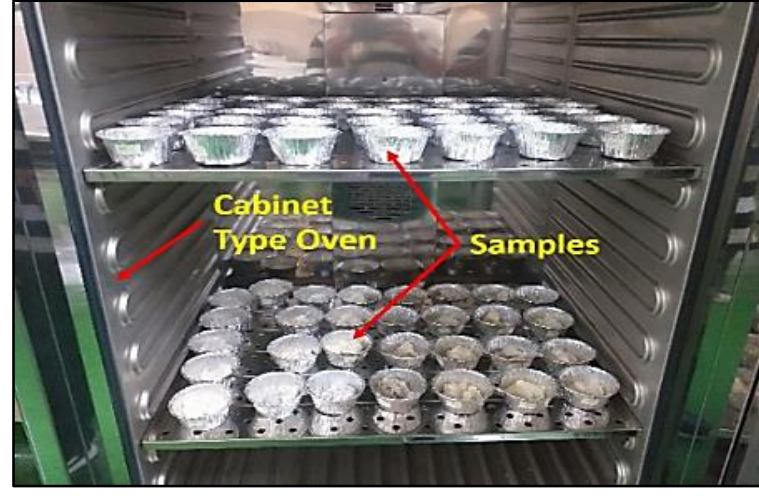

Fig 9. Samples placed in oven for moisture determination.

Table 2. Summary results of the effect of the treatment combination in moisture content and rate of moisture removal

\begin{tabular}{ccccc}
\hline $\begin{array}{c}\text { Run } \\
\#\end{array}$ & $\begin{array}{c}\text { Speed } \\
(\mathrm{rpm})\end{array}$ & $\begin{array}{c}\text { Discharge } \\
\text { Clearance } \\
(\mathrm{mm})\end{array}$ & $\begin{array}{c}\text { Moisture } \\
\text { Content } \\
(\%)\end{array}$ & $\begin{array}{c}\text { Rate of } \\
\text { Moisture } \\
\text { Removal } \\
(\mathrm{kg} / \mathrm{h})\end{array}$ \\
\hline 1 & 27 & 7 & 55.77 & 1.28 \\
2 & 20 & 2 & 46.19 & 3.24 \\
3 & 30 & 5 & 48.08 & 4.33 \\
4 & 20 & 5 & 46.87 & 3.19 \\
5 & 27 & 3 & 52.23 & 5.74 \\
6 & 20 & 5 & 46.10 & 3.01 \\
7 & 13 & 3 & 43.88 & 2.81 \\
8 & 20 & 5 & 46.71 & 3.81 \\
9 & 13 & 7 & 54.05 & 2.53 \\
10 & 20 & 8 & 52.56 & 1.98 \\
11 & 10 & 5 & 50.86 & 3.27 \\
\hline
\end{tabular}

\subsubsection{Moisture Content}

The performance of the combined grater-presser machine in carrying the moisture content of pressed grates into the desired level was determined in relation to presser angular speed and discharge clearance.

The average final moisture content of the pressed grates as Table 2 presented ranged from $43.88 \%$ to $55.77 \%$ wet basis. According to the practice of Philippine Root Crops Center, a moisture content of less than $50 \%$ wet basis is the recommended MC to avoid lumping of the grates during drying. Hence, six (6) treatment combinations from the experiment were of acceptable moisture content. The most acceptable moisture content was achieved with a factor combination of $13 \mathrm{rpm}$ angular speed and $3 \mathrm{~mm}$ discharge clearance. A surface regression model analysis and Analysis of Variance (ANOVA) were conducted to determine the effect of two factors in the measured response. It shows that among several models, a linear model was found to be adequate for the prediction of the moisture content of the pressed grates which was given by the following equation:

Moisture Content $=40.39220+0.10780 *$ Presser Speed $+1.36853 *$ Discharge Clearance

(Eq.8)

However, the Analysis of Variance (ANOVA) as presented in Table 3 for linear model appeared that the model was insignificant. It was then supported by a significant Lack of Fit Test which concluded that the model was not reliable in predicting the response. It also has smaller $\mathrm{R}^{2}$ of about 0.4571 which also meant that the two set variables were not enough in predicting the variability of the response. Analyzing the effect of individual factor, it was shown in the ANOVA that the presser angular speed had no significant effect on the final moisture content of the grates but discharge clearance showed that it can affect the moisture significantly at $95 \%$ level of significance. Such an effect is visible by looking at the surface plot being developed in Figure 10. The decreasing discharge clearance eventually resulted in a much acceptable moisture content. A smaller discharge clearance had a higher counter back pressure which was needed for further pressing.

Table 3. Analysis of Variance (ANOVA) for response surface linear model with moisture content as a response

\begin{tabular}{|c|c|c|c|c|c|}
\hline Source & SS & df & MS & $\begin{array}{c}\text { F- } \\
\text { Value }\end{array}$ & $\begin{array}{c}\text { P- } \\
\text { Value }> \\
\text { F }\end{array}$ \\
\hline Model & 68.28 & 2 & 34.14 & 3.37 & $0.0869^{\mathrm{ns}}$ \\
\hline $\begin{array}{l}\text { A-Presser } \\
\text { Speed } \\
\text { B- }\end{array}$ & 4.60 & 1 & 4.60 & 0.45 & $0.5194^{\mathrm{ns}}$ \\
\hline $\begin{array}{l}\text { Discharge } \\
\text { Clearance }\end{array}$ & 63.68 & 1 & 63.68 & 6.28 & $0.0366^{*}$ \\
\hline Residual & 81.09 & 8 & 10.14 & & \\
\hline $\begin{array}{r}\text { Lack of } \\
\text { Fit }\end{array}$ & 80.76 & 6 & 13.46 & 81.52 & $0.0122^{*}$ \\
\hline $\begin{array}{c}\text { Pure } \\
\text { Error }\end{array}$ & 0.33 & 2 & 0.17 & & \\
\hline Cor Total & 149.37 & 10 & & & \\
\hline
\end{tabular}

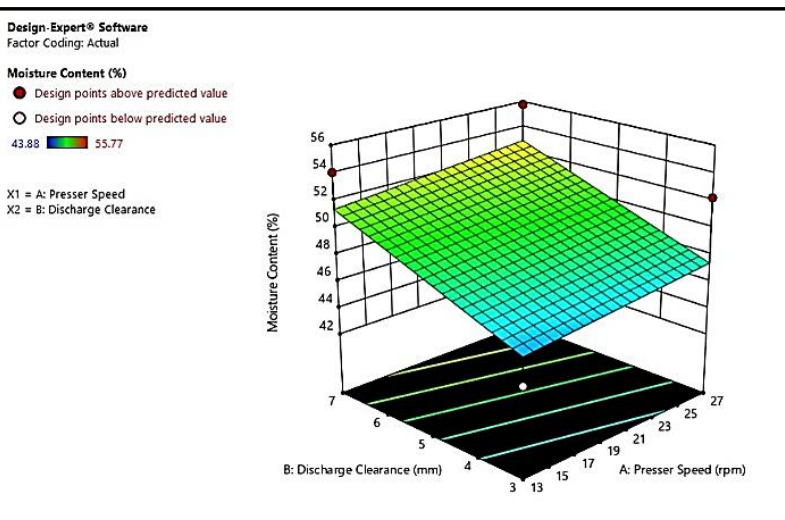

Fig 10. Surface Plot for Moisture Content.

\subsubsection{Rate of Moisture Removal}

As Table 2 presented, the average rate of moisture removal ranged from $1.27 \mathrm{~kg} / \mathrm{h}$ to $5.74 \mathrm{~kg} / \mathrm{h}$. It was determined by dividing the total moisture extracted at the moisture outlet of the presser to the total operating time of the machine. The highest rate of moisture removal was attained at treatment combination of $27 \mathrm{rpm}$ angular speed and $3 \mathrm{~mm}$ discharge clearance. It shows that out of the several models, 2 Factor Interaction (2FI) model (Eq.9) was the most suited model in predicting the rate of moisture removal by the machine in relation to presser 
angular speed and discharge clearance. An Analysis of Variance (ANOVA) for 2FI model was conducted to test the significance of the model and other factors as presented in Table 4. It showed that the model was significant with $\mathrm{R}^{2}$ of 0.7758 at $95 \%$ level of confidence. It was also presented in the table that discharge clearance had a significant linear effect on the rate of moisture removal. It can be seen in surface plot (Fig. 11) that an increase in discharge clearance resulted in a decrease of the rate of moisture removal. Furthermore, the analysis showed that there is a significant interaction between the two independent variables to the rate of moisture removal. It can be seen in the graph that increasing the level of both independent variables (presser angular speed and discharge clearance) led to a decreasing rate of moisture removal. However, increasing speed and decreasing discharge clearance or increasing discharge clearance and decreasing speed both resulted in an increased rate of moisture removal (2-way interaction). It was presented in the previous section that smaller discharge clearance resulted in higher moisture removal. If it was accompanied by higher angular speed, the rate of moisture removal eventually increased since the operating time for higher angular speed was much lower and rate of moisture removal was a function of operating time.

Rate of Moisture Removal $=-3.45437+0.43035 *$ Presser Speed + 1.10487*Discharge Clearance $0.074794 *$ Presser Speed*Discharge Clearance (Eq.9)

Table 4. Analysis of Variance (ANOVA) for response surface 2FI model with rate of moisture removal as a response

\begin{tabular}{|c|c|c|c|c|c|}
\hline Source & SS & df & MS & $\begin{array}{c}\text { F- } \\
\text { Value }\end{array}$ & $\begin{array}{c}\text { P-Value } \\
\text { Prob }> \\
\text { F }\end{array}$ \\
\hline Model & 10.84 & 3 & 3.61 & 8.07 & $0.0113^{*}$ \\
\hline $\begin{array}{l}\text { A-Presser } \\
\text { Speed } \\
\text { B- }\end{array}$ & 1.26 & 1 & 1.26 & 2.81 & $0.1374^{\mathrm{ns}}$ \\
\hline $\begin{array}{l}\text { Discharge } \\
\text { Clearance }\end{array}$ & 5.20 & 1 & 5.20 & 11.61 & $0.0113^{*}$ \\
\hline $\mathrm{AB}$ & 4.39 & 1 & 4.39 & 9.80 & $0.0166^{*}$ \\
\hline Residual & 3.13 & 7 & 0.45 & & \\
\hline $\begin{array}{r}\text { Lack of } \\
\text { Fit }\end{array}$ & 2.78 & 5 & 0.56 & 3.15 & $0.2582^{\mathrm{ns}}$ \\
\hline $\begin{array}{l}\text { Pure } \\
\text { Error }\end{array}$ & 0.35 & 2 & 0.18 & & \\
\hline Cor Total & 13.98 & 10 & & & \\
\hline
\end{tabular}

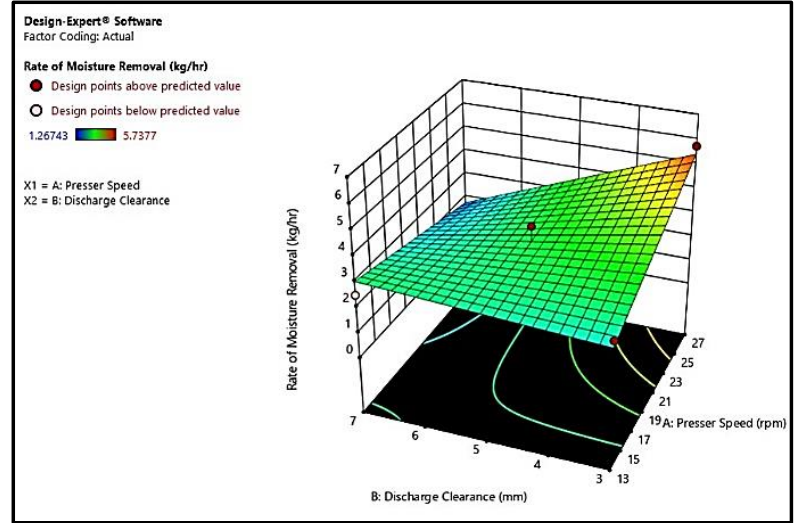

Fig 11. Surface Plot for Rate of Moisture Removal.

\section{CONCLUSIONS}

The study focused in the comparative evaluation of different screw types which is needed for the development of the combined grater-presser machine. The study shows among all other screw, the variable pitch screw is not suited for the combined grater-presser machine since it develop too much pressure which leads to failure of some machine elements. Excessive pressure also could lead to the gelatinization of cassava grates. Moreover, the tapered screw is the most suited type of screw to be used in the development of the combined grater-presser machine. In the second experiment, the evaluation of the machine using the tapered screw were conducted with varying angular speed and discharge clearance. It was presented in the results that the machine performance is highly affected by this two factors in terms of moisture removal. The developed surface plot shows the relation of this factors. It was shown that the relation of the two factors is linear in terms of final moisture content of the product. Moreover, it was also presented that the rate of moisture removal can be explained by two-factor interaction model. In summary, tapered screw is the best screw for the machine and the angular speed and discharge clearance can highly affect the machine performance.

\section{REFERENCES}

[1] KADURUMBA, C.H., T.M. OGUNSOL, AND C.G. NWOGU-CHIBUIKE. 2018. Design Modification of a Cassava Dewatering Machine. Nigerian Research Journal of Engineering and Environmental Sciences. Vol.3(1). pp.18-31.

[2] KOlAwOle, O. PETER, L. AGBetoye, A.S. OGUNLOWO, L.SANNI and A.ADEBAYO. 2012. Innovative Development of Cassava Processing Machine as Solution to Crisis against Agricultural Systems. Conference on International Research on Food Security, Natural Resource Management and Rural Development. GOTTINGEN, GERMANY. pp. 1-4.

[3] KOLAWOLE O.P., L.A. AGBETOYE, A.S. OGUNLOWO, and T.M. SAMUEL. 2012. Effect of Speed and Back Pressure on the Performance of the Screw Press in Dewatering of Cassava Mash. Greener Journal of Science Engineering and Technological Research. ISSN:2276-7835. pp. 17-23. 
[4] Loreto AB. And Orias RR. 2001. New Products of Future Potential in the Philippines: Cassava Flour and Grates. Accessed 20 March 2018 from http://ciatlibrary.ciat.cgiar.org/Articulos_Ciat/Digita 1/SB123.E9C.2_An_exchange_of_experiences_from _South_and_South_East_Asia.pdf\#page $=567$

[5] SARI, P. 2006. Preliminary Design and Construction of a Prototype Canola Seed Oil Extraction Machine. MSc Thesis. Middle East Technical University. Turkey 